\title{
Application of MALDI-TOF mass spectrometry in clinical diagnostic microbiology
}

\author{
Elena De Carolis ${ }^{1}$, Antonietta Vella ${ }^{1}$, Luisa Vaccaro ${ }^{1}$, Riccardo Torelli ${ }^{1}$, Teresa Spanu ${ }^{1}$, Barbara Fiori ${ }^{1}$, \\ Brunella Posteraro ${ }^{2}$, Maurizio Sanguinetti ${ }^{1}$ \\ ${ }^{1}$ Institute of Microbiology, Catholic University of the Sacred Hearth, Rome, Italy \\ ${ }^{2}$ Institute of Hygiene, Catholic University of the Sacred Hearth, Rome, Italy
}

\begin{abstract}
Matrix-assisted laser desorption/ionization-time of flight mass spectrometry (MALDI-TOF MS) has recently emerged as a powerful technique for identification of microorganisms, changing the workflow of well-established laboratories so that its impact on microbiological diagnostics has been unparalleled.

In comparison with conventional identification methods that rely on biochemical tests and require long incubation procedures, MALDI-TOF MS has the advantage of identifying bacteria and fungi directly from colonies grown on culture plates in a few minutes and with simple procedures.

Numerous studies on different systems available demonstrate the reliability and accuracy of the method, and new frontiers have been explored besides microbial species level identification, such as direct identification of pathogens from positive blood cultures, subtyping, and drug susceptibility detection.
\end{abstract}

Key words: MALDI-TOF MS; diagnostic microbiology; subtyping; antimicrobial resistance.

J Infect Dev Ctries 2014; 8(9):1081-1088. doi:10.3855/jidc.3623

(Received 07 April 2013 - Accepted 12 december 2013)

Copyright (C) 2014 De Carolis et al. This is an open-access article distributed under the Creative Commons Attribution License, which permits unrestricted use, distribution, and reproduction in any medium, provided the original work is properly cited.

\section{Introduction}

Mass spectrometry (MS) technology has been used for several decades in chemistry. In 1975, Anhalt and Fenselau suggested the use of this tool for bacterial characterization, as they observed that different and unique mass spectra were produced from bacterial extracts of different genera and species [1]. In the 1980s, desorption/ionization techniques (plasma desorption, laser desorption, and fast atom bombardment) that allow the generation of molecular biomarker ions from microorganisms were developed, opening the road for bacterial profiling $[2,3]$. The first experiments were based on a biomolecule ionization processes that allowed the generation of biomarker molecules of low molecular masses [4,5], mostly bacterial lipids. Only in the late 1980s, Tanaka and Fenn, thanks to the development of soft ionization techniques (matrix-assisted laser desorption/ionization [MALDI] and electrospray ionization), made possible the analysis of large biomolecules such as intact proteins [6,7]. For the first time, in 1996, MALDI-time of flight (TOF) spectral fingerprints could be obtained from whole bacterial cells by Holland et al., avoiding pretreatment before the MS analysis [8]. Nowadays, the matrix-assisted laser desorption ionization time-offlight mass spectrometry (MALDI-TOF MS) has emerged as a rapid, accurate, and sensitive tool for microbial characterization and identification of bacteria, fungi, and viruses [9], as demonstrated by the exponential number of publications about the issue.

This review provides an overview of the literature on the topic.

\section{Technical description of MALDI-TOF MS}

MALDI ionization is a soft ionization technique that allows ionization and vaporization of large nonvolatile biomolecules such as intact proteins [10]. It generates mostly single-charged ions $(z=1)$ so that the mass-to-charge ratio $(\mathrm{m} / \mathrm{z})$ of the analyte corresponds to its mass value.

Each MALDI-TOF mass spectrometer is composed of three principal units. The first is the ion source that makes ionization possible and transfers sample molecule ions into a gas phase. The second unit is the mass analyzer that allows ion separation 
according to $\mathrm{m} / \mathrm{z}$. The last unit is a detection device for monitoring separated ions.

Samples are prepared by mixing the analyte with a matrix made of small acid molecules that possesses a strong optical absorption in the range of the wavelength used by the laser device; DHB 2,5dihydroxybenzoic acid and CHCA $\alpha$-cyano-4hydroxycinnamic acid are optimal matrices for the detection of lower mass ions. After co-crystallization of the sample and matrix, the latter absorbs energy from the laser, leading to the desorption and ionization of the analytes in the gas phase. Ions are then accelerated through an electrostatic field (created by a potential of about $20 \mathrm{kV}$ ) into the high vacuum flight tube until they reach the detector, with smaller ions traveling faster than larger ones. Thus, the time of flight (TOF) required to reach the detector is dependent on the mass and charge of the bioanalyte, resulting in a spectral profile unique for a given species, composed of peaks ranging usually from 2 to $20 \mathrm{kDa}$.

Very conserved proteins with housekeeping functions comprise the MALDI-TOF spectra. Detected biomolecules correspond mostly to ribosomal proteins that are abundant, basic, and of medium hydrophobicity [11], all biochemical traits that favor efficient ionization. Among the proteins ionized during the MALDI process are structural proteins, DNA or RNA binding proteins [12,13], ribosome modulation factors, carbon storage regulators, coldshock proteins, and translation initiation factors. These biomarkers generate spectral fingerprints that vary between microorganisms and have peaks specific to genus, species, and subspecies.

For microorganism identification, protein mass patterns are compared within a few minutes with commercially available reference databases (Bruker Daltonics for Microflex LT spectrometer and Vitek MS for bioMérieux spectrometer, the latest developed by Shimadzu (Shimadzu-Biotech Corp., Kyoto, Japan), which include species-specific fingerprints of several bacterial and yeast isolates. Through a pattern matching procedure, mass peaks in the experimental spectra are matched with reference spectra included in the database; through this comparison, a numerical value is generated that allows accurate and rapid identification of the microorganisms to species level when score values obtained are in the range of the threshold values defined by the instrument manufacturer (score values higher than 2.0 for Bruker Biotyper software and higher than $90 \%$ for VITEKMS, respectively). The identification process is performed in real time, as soon as the sample is analyzed by the spectrometer $[14,15]$.

\section{Bacterial identification}

Routine laboratory techniques for microorganism identification in clinical diagnosis are mainly based on biochemical tests, microscopy, interpretation of bacteria phenotypic characteristics or, alternatively, on molecular biology. These analyses require expertise and are time-consuming.

MALDI-TOF technology allows accurate bacterial identification of a large variety of species in reduced time, from between 24 and 48 hours to a few minutes, with a small amount of microbial biomass required for the analysis $\left(10^{4}\right.$ to $\left.10^{6} \mathrm{CFU}\right)$. Bacterial isolate colonies are picked from agar medium with a sterile tip and smeared in a thin film onto a ground steel MALDI target plate, overlaid with CHCA (for the Bruker instrument) or DHB (for the Vitek MS instrument), and introduced in the mass spectrometer for data acquisition. Spectra are compared with those present in the reference database, with a short time to results. The two systems produce comparable results, and overall the MALDI-TOF identification performance is significantly better $(93.2 \%)$ than that of BD Phoenix (Becton Dickinson Diagnostic Systems, France) $(75.6 \%)$ and Vitek-2 (bioMérieux, Marcy L'Etoile, France) (75.2\%) [16]. Species with a low rate of differences in their ribosomal protein sequences such as Shigella spp., Escherichia coli, some strains of Stenotrophomonas maltophilia, Propionibacterium acnes or Streptococcus pneumoniae, and members of the $S$. oralis/mitis group can be misidentified by MALDI-TOF MS. To date, the accuracy of the identification depends greatly on the number of database entries; an update of the reference database is needed to improve the identification performance of MALDI-TOF.

Improving database entries with multiple spectra of well-characterized species will allow an identification rate close to $100 \%$ for Neisseria, Clostridia, Mycobacteria, Salmonella, viridans group streptococci, Helicobacter pylori, and Campylobacter [17]. Reliable identification and classification of cultured Mycobacteria can also be obtained by MALDI-TOF MS using an adequate database [18].

\section{Yeast and fungi identification}

As yeasts possess a thick cell wall, its disruption requires an additional extraction step compared to bacterial protocol, with some differences between the two available systems. Briefly, for the Bruker system, 
colonies are picked and inoculated in $70 \%$ ethanol, the suspension is pelleted, dried, and resuspended in $70 \%$ formic acid and acetonitrile. After a centrifugation step, one microliter of supernatant is applied on the MALDI target plate and dried, covered with matrix, and analyzed. For the Vitek MS system, colonies are directly smeared onto the plate and lysed with $25 \%$ formic acid before matrix deposition.

Bruker and Vitek MS commercially available databases contain reference spectra of the yeasts most commonly isolated in the clinical laboratory, including several Candida spp. and Cryptococcus neoformans strains.

Many studies have demonstrated that MALDITOF MS successfully differentiates yeast isolates [1921], with a similar species identification rate for Bruker and Shimadzu systems - 97.6\% and 96.1\%, respectively [22] - with results comparable with those of biochemical analysis (96.9\%). MALDI-TOF MS has the ability to distinguish within the $C$. glabrata clade (C. glabrata, $C$. nivariensis, and $C$. bracarensis) and between members of the psilosis complex $(C$. parapsilosis, C. metapsilosis, and C. orthopsilosis) whose identification currently depends on molecular methods as biochemical ones do not allow the separation of these species [23] - as well as between C. albicans and C. dubliniensis. For Cryptococcus neoformans, an unreliable identification rate has been reported in comparison with biochemical methods [24], probably due to the problematic extraction and solubilization of this pathogen's proteins caused by its polysaccharide capsule and the insufficient database entries. Implementation of database entries, however, assures good identification performance also for $C$. neoformans and C. gattii species [25].

Fungi are difficult to identify because of their biological complexity and because of the continuous classification changes due to the introduction of nucleic acid-based methodology able to detect cryptic species [26]. Filamentous fungi exhibit different phenotypes depending on their growth conditions, secondary metabolite production, and the portion of mycelium or conidia taken for the analysis, making their protein extraction difficult and peak reproducibility low. In view of these considerations, it is not surprising that relatively few studies have been conducted regarding filamentous fungi and very few reference spectra have been included in commercially available mass spectrometer databases.

However, some recent publications have demonstrated the applicability of the MALDI-TOF MS technology to the differentiation of clinical fungi such as Aspergillus, Penicillium, Fusarium, and dermatophytes [27] using reference databases built inhouse and performing analysis on accurately pretreated samples to enhance the performance of the identification.

The samples to be analyzed are suspended in $75 \%$ ethanol solution, centrifuged, and suspended in formic acid and acetonitrile. The supernatant is centrifuged and spotted on the MALDI target plate. Moreover, quick extraction protocols on intact cells have been developed to reduce analysis time, applying the fungal suspension directly onto the target plate [28] and overcoming the problem of the age of the colonies, which reflects different protein composition, by an accurate database update with spectra of young and mature colonies [29].

\section{Direct identification in samples}

The identification of microorganisms directly from biological samples is the next challenge of this technique, as the early establishment of an appropriate antimicrobial therapy will enhance patient survival rates and reduce costs of clinical patient management.

Molecular assays, such as the probe-based test (PNA-FISH) and nucleic acid amplification-based tests (PCR), have been applied to the identification of pathogens directly from blood cultures, but these are limited to the detection of some specific targets and are expensive or difficult to manage [30].

Until now, MALDI-TOF performance based on differentiation of pathogens directly from positive blood cultures has been investigated in a number of works [31]; there have been much fewer studies using direct urine samples.

As blood samples present high concentrations of host proteins that may interfere with the detection of specific bacterial and fungal proteins, cell lysis protocol or differential centrifugation steps have been developed to obtain reliable levels of identification [32-35] aside from the use of a commercial kit called Sepsityper with a limit of detection of $5.9 \times 10^{5} \mathrm{CFU}$ Bruker Daltonics (Bruker, Bremen, Germany) [36].

Rapid identification has been achieved with greater success for Gram-negative organisms than Gram-positive ones [37], and, overall, the identification rate showed variable results ranging from $75 \%$ to $95 \%$ for monomicrobial blood cultures. The difference in Gram-negative and Gram-positive scores is probably due to the different composition in the peptidoglycan layer of the Gram-positive bacterial cell wall; some authors have proposed to treat bacteria with ultrasound [38] to improve Gram-positive 
identification results or to lower criteria adopted for acceptable scores at the species level [39].

For yeasts identification directly from blood culture bottles, results are concordant with those of the conventional culture-based method for $95.9 \%$ of Candida albicans and $86.5 \%$ of non-albicans Candida species [34].

MALDI-TOF MS has also been successfully used for direct identification of bacteria from primary urine specimens, although an initial flow cytometer-based screening is needed to eliminate negative urine samples and perform MALDI-TOF analysis on samples reporting a bacterial load $>10^{5} \mathrm{CFU} / \mathrm{mL}$ only. The protocol consist of a slow centrifugation step to pellet out leukocytes, and a faster centrifugation step to collect bacteria, followed by a washing in distilled water prior to analysis of samples with a MALDI-TOF MS. Rates of identification are high, reaching 91.8\% for bacterial load higher than $10^{5} \mathrm{CFU} / \mathrm{mL}[40,41]$.

\section{Detection of antimicrobial resistance}

MALDI-TOF MS technology opened new frontiers in diagnostic microbiology and resistant microorganism detection.

One of the more interesting topics is methicillin- resistant Staphylococcus aureus (MRSA). Although some studies showed the ability of mass spectrometry to distinguish between methicillin-susceptible and resistant $S$. aureus $[42,43]$, conflicting data have been published on the issue $[44,45]$.

Regarding the detection of $\beta$-lactamase production in Enterobacteriaceae, an interesting approach involves the detection of cleavage products produced by $\beta$-lactam rings hydrolysis. Hydrolysis is made by the bacterial enzymes eventually present and after an incubation (from one to three hours) of the bacteria with the antibiotic to be tested. A shift in the mass of the antibiotic compound is produced, which can be detected by the MALDI-TOF mass spectrometer, confirming the presence of a $\beta$-lactamase (Figure 1) [46-48].

Regarding carbapenemases, MALDI-TOF MS was found to be suitable for differentiating $B$. fragilis strains, which harbor the $c f i \mathrm{~A}$ gene, from those that do not [49].

Regarding yeasts changes in the proteome profile have been detected by MALDI-TOF MS after $C$. albicans exposure to different antifungal fluconazole drug concentrations (corresponding to its fluconazole MIC, measured with conventional

Figure 1. Schematic representation of antimicrobial resistance detection workflow by MALDI-TOF MS approach for Enterobacteriaceae and Candida. In the upper part of the figure, a mass shift in the spectra profile of the antibiotic tested reveals the presence of carbapenemases in the $\beta$-lactamase-positive strain. In the lower part of the figure, two possible matrices obtained from Candida susceptible and resistant strains by composite correlation index analysis of the spectra profiles acquired from isolates exposed at high concentration, no drug and breakpoint test concentration of antifungals, are shown.

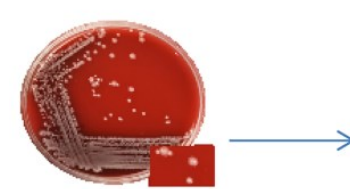

Resuspension in

antibiotic solution

\section{Enterobacteriaceae}

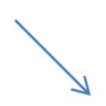

MALDI-TOF spectra acquisition

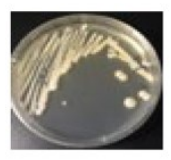

Resuspension in antifungal solution
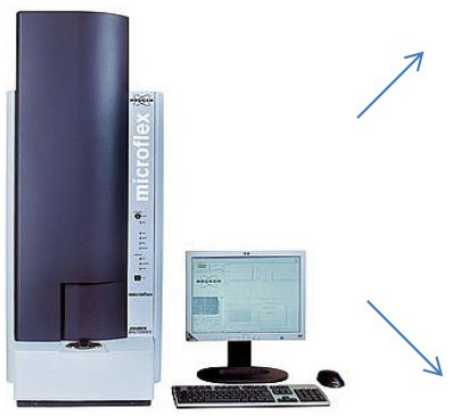
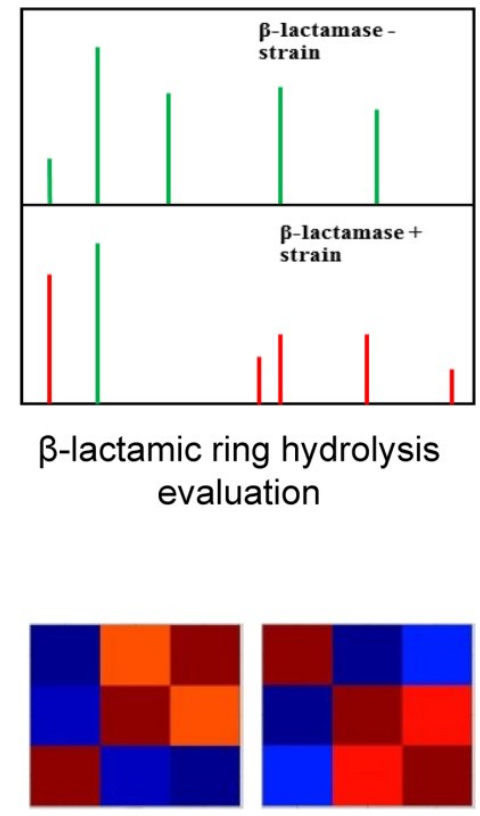

Composite correlation index $(\mathrm{CCl})$ evaluation 
methods) [50], so that this technology is promising for future application, especially for the detection of emerging resistant pathogenic fungi. Moreover, comparison of spectra profiles of Candida and Aspergillus strains exposed to serial dilution of caspofungin by composite correlation index analysis allowed detection of fungal isolates with reduced caspofungin susceptibility, leading to a correct categorization of FKS mutant and wild-type isolates of C. albicans after an incubation time of only three hours, thus confirming the reliability of MALDI-TOF MS for antifungal susceptibility testing (Figure 1) $[51,52]$.

\section{Subtyping}

Differentiation of isolates below the species level is important for epidemiological analysis. Most subtyping methods are based on the use of a restriction enzyme (ribotyping, PFGE, AFLP) or a PCR-based technique (RAPD, REP and ERIC elements-based PCR, MLST); all these techniques possess different discriminatory powers, and their use depends on the final objective to be achieved.

Overall, these applications are highly expensive, time-consuming, and sometimes present a low level of reproducibility.

Differences between protein spectra can be used for individual strain typing by MALDI-TOF MS, as reported in recent studies on Salmonellae [12], Francisella tularensis [53], Bacterioides fragilis [49], Streptococcus agalactiae [54], Acinetobacter baumannii [55,56], Yersinia enterocolitica [57], Staphylococci [58], and Cryptococcus [25]. Each spectrum is compared with another through a matrix of cross-wise identification values that are used to calculate the distance values for each spectra pair. On the basis of these values, a mass spectrometry-based dendrogram is generated, in which closely related strains can be separated hierarchically according to their mass signals and intensities.

Because of its speed, ease of use, and low costs, MALDI-TOF MS potential in microorganism typing has to be further explored to determine the level of its discriminatory power.

\section{Concluding remarks}

Recently, the availability of simple-to-use MALDI-TOF MS devices in clinical microbiology laboratories has changed routine identification workflows of pathogenic bacteria, yeasts, and, to a lesser extent, fungi. Although all prospective studies show that MALDI-TOF MS correctly identifies the great majority of isolates processed routinely, discrepancies between MALDI-TOF MS-based identification results and biochemical or molecular tests have been observed for the identification of Shigella species, pneumococci, and viridans streptococci. To increase MALDI-TOF MS power, database upgrades and sample enrichment are important. For yeasts, an extraction step is mandatory on the day prior to analysis. Because of the low consumable costs and the speed of MALDI-TOF MS, the technique can improve laboratory performance for clinical sample management; otherwise, the high cost of the equipment makes mass spectrometry suitable only for big hospitals. Further prospective studies are warranted to increase MALDI-TOF MS reliability to directly identify pathogens in biological fluids, such as urine samples and blood cultures. However, this technique has the potential to identify clinical samples at the serotype or strain level, and is a good candidate to open the road for antibiotic resistance profiling within minutes in the years to come.

\section{Acknowledgements}

This review was written in honor of Professor Giovanni Fadda.

This work was funded by FIRB grant from the Ministry of Education and Research (MIUR) Nr. RBFR100FLV_002.

\section{References}

1. Anhalt J.P., Fenselau C. (1975) Identification of bacteria using mass spectrometry. Anal. Chem., 47: 219-225.

2. Heller DN, Cotter RJ, Fenselau C (1987) Profiling of bacteria by fast-atom-bombardment mass-spectrometry. Anal Chem 59: 2806-2809.

3. Platt JA, Uy OM, Heller DN, Cotter RJ, Fenselau C (1988) Computer-based linear-regression analysis of desorption mass-spectra of microorganisms. Anal Chem 60: 1415-1419.

4. Shah HN, Collins MD (1980) Fatty acid and isoprenoid quinone composition in the classification of Bacteroides melaninogenicus and related taxa. J Appl Bacteriol 48: 75-87.

5. Heller DN, Murphy C, Cotter RJ, Fenselau C, Uy OM (1988) Constant neutral loss scanning for the characterization of bacterial phospholipids desorbed by fast atom bombardment. Anal Chem 60: 2787-2791.

6. Tanaka K, Waki H, Ido Y, Akita S, Yoshida Y, Yoshida T and Matsuo T (1988) Protein and polymer analyses up to $\mathrm{m} / \mathrm{z}$ 100000 by laser ionization time-of-flight mass spectrometry. Rapid Commun Mass Spectrom 2: 151-153.

7. Fenn JB, Mann M, Meng CK, Wong SF and Whitehouse CM (1990) Electrospray ionization-principles and practice Mass Spectrom Rev 9: 37-70.

8. Holland RD, Wilkes JG, Rafii F, Sutherland JB, Persons CC, Voorhees KJ, Lay JO Jr (1996) Rapid identification of intact whole bacteria based on spectral patterns using matrix- 
assisted laser desorption/ionization with time-of-flight mass spectrometry. Rapid Commun Mass Spectrom 10: 1227-1232.

9. Giebel R, Worden C, Rust SM, Kleinheinz GT, Robbins M, Sandrin TR (2010) Microbial fingerprinting using matrix assisted laser desorption ionization time-of-flight mass spectrometry (MALDI-TOF MS) applications and challenges. Adv Appl Microbiol 71: 149-184.

10. Emonet S, Shah HN, Cherkaoui A, Schrenzel J (2010) Application and use of various mass spectrometry methods in clinical microbiology. Clin Microbiol Infect 16: 1604-1613.

11. Ryzhov V, Fenselau C (2001) Characterization of the protein subset desorbed by MALDI from whole bacterial cells. Anal Chem 73: 746-750.

12. Dieckmann R, Malorny B (2011) Rapid screening of epidemiologically important Salmonella enterica subsp. enterica serovars using Whole-Cell MALDI-TOF mass spectrometry. Appl Environ Microbiol 77: 4136-4146.

13. Dieckmann R, Helmuth R, Erhard M, Malorny B (2008) Rapid classification and identification of salmonellae at the species and subspecies levels by whole-cell matrix-assisted laser desorption ionization-time of flight mass spectrometry. Appl Environ Microbiol 74: 7767-7778.

14. Jarman KH, Cebula ST, Saenz AJ, Petersen CE, Valentine NB, Kingsley MT, Wahl KL (2000) An algorithm for automated bacterial identification using matrix-assisted laser desorption/ionization mass spectrometry. Anal Chem 72: 1217-1223.

15. Sauer S, Freiwald A, Maier $T$, Kube M, Reinhardt R, Kostrzewa M, Geider K (2008) Classification and identification of bacteria by mass spectrometry and computational analysis. PLoS One 3: e2843.

16. Dupont C, Sivadon-Tardy V, Bille E, Dauphin B, Beretti JL, Alvarez AS, Degand N, Ferroni A, Rottman M, Herrmann JL, Nassif X, Ronco E, Carbonnelle E (2010) Identification of clinical coagulase-negative staphylococci, isolated in microbiology laboratories, by matrix-assisted laser desorption/ionization-time of flight mass spectrometry and two automated systems. Clin Microbiol Infect 16: 998-1004.

17. Wieser A, Schneider L, Jung J, Schubert S (2012) MALDITOF MS in microbiological diagnostics-identification of microorganisms and beyond (mini review). Appl Microbiol and Biotechnol 93: 965-974.

18. Pignone M, Greth KM, Cooper J, Emerson D, Tang J (2006) Identification of mycobacteria by matrix-assisted laser desorption ionization-time-of-flight mass spectrometry. J Clin Microbiol 44: 1963-1970.

19. Marklein G, Josten M, Klanke U, Müller E, Horré R, Maier T, Wenzel T, Kostrzewa M, Bierbaum G, Hoerauf A, Sahl HG (2009) Matrix-assisted laser desorption ionization-time of flight mass spectrometry for fast and reliable identification of clinical yeast isolates. J Clin Microbiol 47: 2912-2917.

20. Bizzini A, Greub G (2010) Matrix-assisted laser desorption ionization time-of-flight mass spectrometry, a revolution in clinical microbial identification. Clin Microbiol Infect 16: 1614-1619.

21. van Veen SQ, Claas EC, Kuijper EJ (2010) High-throughput identification of bacteria and yeast by matrix-assisted laser desorption ionization-time of flight mass spectrometry in conventional medical microbiology laboratories. J Clin Microbiol 48: 900-907.

22. Bader O, Weig M, Taverne-Ghadwal L, Lugert R, Groß U, Kuhns M (2011) Improved clinical laboratory identification of human pathogenic yeasts by matrix-assisted laser desorption ionization time-of-flight mass spectrometry. Clin Microbiol Infect 17: 1359-1365.

23. Pinto A, Halliday C, ZahraM, van Hal S, Olma T, Maszewska K, Iredell JR, Meyer W, Chen SC (2011) Matrix-assisted laser desorption ionization-time of flight mass spectrometry identification of yeasts is contingent on robust reference spectra. PLoS One 6: e25712.

24. Stevenson LG, Drake SK, Shea YR, Zelazny AM, Murray PR (2010) Evaluation of matrix-assisted laser desorption ionization-time of flight mass spectrometry for identification of clinically important yeast species. J Clin Microbiol 48: 3482-3486.

25. Posteraro B, Vella A, Cogliati M, De Carolis E, Florio AR, Posteraro P, Sanguinetti M, Tortorano AM (2012) Matrixassisted laser desorption ionization-time of flight mass spectrometry-based method for discrimination between molecular types of Cryptococcus neoformans and Cryptococcus gattii. J Clin Microbiol 50: 2472-2476.

26. Hibbett DS, Binder M, Bischoff JF, Blackwell M, Cannon PF, Eriksson OE, Huhndorf S, James T, Kirk PM, Lücking R, Thorsten Lumbsch H, Lutzoni F, Matheny PB, McLaughlin DJ, Powell MJ, Redhead S, Schoch CL, Spatafora JW, Stalpers JA, Vilgalys R, Aime MC, Aptroot A, Bauer R, Begerow D, Benny GL, Castlebury LA, Crous PW, Dai YC, Gams W, Geiser DM, Griffith GW, Gueidan C, Hawksworth DL, Hestmark G, Hosaka K, Humber RA, Hyde KD, Ironside JE, Kõljalg U, Kurtzman CP, Larsson KH, Lichtwardt R, Longcore J, Miadlikowska J, Miller A, Moncalvo JM, Mozley-Standridge S, Oberwinkler F, Parmasto E, Reeb V, Rogers JD, Roux C, Ryvarden L, Sampaio JP, Schüssler A, Sugiyama J, Thorn RG, Tibell L, Untereiner WA, Walker C, Wang Z, Weir A, Weiss M, White MM, Winka K, Yao YJ, Zhang N (2007) A higher-level phylogenetic classification of the Fungi. Mycol Res 111: 509-547.

27. Santos C, Paterson RMR, Venâncio A, Lima N (2010) Filamentous fungal characterizations by matrix-assisted laser desorption/ionization time of flight mass spectrometry. J Appl Microbiol 108: 375-385.

28. Haigh J, Degun A, Eydmann M, Millar M, Wilks M (2011) Improved Performance of Bacterium and Yeast Identification by a Commercial Matrix-Assisted Laser Desorption Ionization-Time of Flight Mass Spectrometry System in the Clinical Microbiology Laboratory. J Clin Microbiol 49: 3441.

29. De Carolis E, Posteraro B, Lass-Flörl C, Vella A, Florio AR, Torelli R, Girmenia C, Colozza C, Tortorano AM, Sanguinetti M, Fadda G (2012) Species identification of Aspergillus, Fusarium and Mucorales with direct surface analysis by matrix-assisted laser desorption ionization time-of-flight mass spectrometry. Clin Microbiol Infect 18: 475-484.

30. Walsh JD, Hyman MJ, Borzhemskaya L, Bowen A, McKellar C, Ullery M, Mathias E, Ronsick C, Link J, Wilson M, Clay B, Robinson R, Thorpe T, van Belkum A, Dunne WM Jr (2013) Rapid Intrinsic Fluorescence Method for Direct Identification of Pathogens in Blood Cultures. mBio 4: 6.

31. La Scola B, Raoult D (2010) Direct identification of bacteria in positive blood culture bottles by matrix-assisted laser desorption ionization time-of-flight mass spectrometry. PLoS One 4: e8041.

32. Christner M, Rohde H, Wolters M, Sobottka I, Wegscheider K, Aepfelbacher M (2010) Rapid identification of bacteria from positive blood culture bottles by use of matrix-assisted laser desorption-ionization time of flight mass spectrometry fingerprinting. J Clin Microbiol 48: 1584-1591. 
33. Ferroni A, Suarez S, Beretti JL, Dauphin B, Bille E, Meyer J, Bougnoux ME, Alanio A, Berche P, Nassif X (2010) Realtime identification of bacteria and Candida species in positive blood culture broths by matrix-assisted laser desorption ionization-time of flight mass spectrometry. J Clin Microbiol 48: 1542-1548.

34. Spanu T, Posteraro B, Fiori B, D'Inzeo T, Campoli S, Ruggeri A, Tumbarello M, Canu G, Trecarichi EM, Parisi G, Tronci M, Sanguinetti M, Fadda G (2012) Direct maldi-tof mass spectrometry assay of blood culture broths for rapid identification of Candida species causing bloodstream infections: an observational study in two large microbiology laboratories. J Clin Microbiol 50: 176-179.

35. Schubert S, Weinert K, Wagner C, Gunzl B, Wieser A, Maier T, Kostrzewa M (2011) Novel, improved sample preparation for rapid, direct identification from positive blood cultures using matrix-assisted laser desorption/ionization time-offlight (MALDI-TOF) mass spectrometry. J Mol Diagn 13: 701-706.

36. Yan Y, He Y, Maier T, Quinn C, Shi G, Li H, Stratton CW, Kostrzewa M, Tang YW (2011) Improved identification of yeast species directly from positive blood culture media by combining Sepsityper specimen processing and Microflex analysis with the matrix-assisted laser desorption ionization Biotyper system. J Clin Microbiol 49: 2528-2532.

37. Martiny D, Dediste A, Vandenberg O (2012) Comparison of an in-house method and the commercial Sepsityper ${ }^{\text {TM }}$ kit for bacterial identification directly from positive blood culture broths by matrix-assisted laser desorption-ionization time-offlight mass spectrometry. Eur J Clin Microbiol Infect Dis 31: 2269-2281.

38. Klein S, Zimmermann S, Köhler C, Mischnik A, Alle W, Bode KA (2012) Integration of matrix-assisted laser desorption/ionization time-of-flight mass spectrometry in blood culture diagnostics: a fast and effective approach. J Med Microbiol 61: 323-331.

39. Moussaoui W, Jaulhac B, Hoffmann A M, Ludes B, Kostrzewa M, Riegel P, Prévost G (2010) Matrix-assisted laser desorption ionization time-of-flight mass spectrometry identifies $90 \%$ of bacteria directly from blood culture vials. Clin Microbiol Infect 16: 1631-1638.

40. Ferreira L, Sánchez-Juanes F, González-Avila M, CembreroFuciños D, Herrero-Hernández A, González-Buitrago JM, Muñoz-Bellido JL (2010) Direct identification of urinary tract pathogens from urine samples by matrix-assisted laser desorption ionization-time of flight mass spectrometry. J Clin Microbiol 48: 2110-2115.

41. Wang XH, Zhang G, Fan YY, Yang X, Sui WJ, Lu XX (2013) Direct identification of bacteria causing urinary tract infections by combining matrix-assisted laser desorption ionization-time of flight mass spectrometry with UF-1000i urine flow cytometry. J Microbiol Methods. 92: 231-235.

42. Edwards-Jones V, Claydon MA, Evason DJ, Walker J, Fox AJ, Gordon DB (2000) Rapid discrimination between methicillin-sensitive and methicillin-resistant Staphylococcus aureus by intact cell mass spectrometry. J Med Microbiol 49: 295-300.

43. Majcherczyk PA, McKenna $T$, Moreillon $P$, Vaudaux $P$ (2006) The discriminatory power of MALDI-TOF mass spectrometry to differentiate between isogenic teicoplaninsusceptible and teicoplanin-resistant strains of methicillinresistant Staphylococcus aureus. FEMS Microbiol Lett 255: 233-239.
44. Bernardo K, Pakulat N, Macht M, Krut O, Seifert H, Fleer S, Hünger F, Krönke M (2002) Identification and discrimination of Staphylococcus aureus strains using matrix-assisted laser desorption/ionization-time of flight mass spectrometry. Proteomics 2: 747-753.

45. Wolters M, Rohde H, Maier T, Belmar-Campos C, Franke G, Scherpe S, Aepfelbacher M, Christner M (2011) MALDITOF MS fingerprinting allows for discrimination of major methicillin-resistant Staphylococcus aureus lineages. Int J Med Microbiol 301: 64-68.

46. Burckhardt I, Zimmermann S (2011) Using matrix-assisted laser desorption ionization-time of flight mass spectrometry to detect carbapenem resistance within 1 to 2.5 hours. J Clin Microbiol 49: 3321-3324.

47. Hrabák J, Walková R, Studentová V, Chudácková E, Bergerová T (2011) Carbapenemase activity detection by matrix-assisted laser desorption ionization-time of flight mass spectrometry. J Clin Microbiol 49: 3222-3227.

48. Sparbier K, Schubert S, Weller U, Boogen C, Kostrzewa M (2012) Matrix-assisted laser desorption ionization-time of flight mass spectrometry-based functional assay for rapid detection of resistance against $\beta$-lactam antibiotics. J Clin Microbiol 50: 927-937.

49. Nagy E, Becker S, Sóki J, Urbán E, Kostrzewa M (2011) Differentiation of division I (cfiA-negative) and division II (cfiA-positive) Bacteroides fragilis strains by matrix-assisted laser desorption/ionization time-of-flight mass spectrometry. $\mathrm{J}$ Med Microbiol 60: 1584-1590.

50. Marinach C, Alanio A, Palous M, Kwasek S, Fekkar A, Brossas JY, Brun S, Snounou G, Hennequin C, Sanglard D, Datry A, Golmard JL, Mazier D (2009) MALDI-TOF MSbased drug susceptibility testing of pathogens: the example of Candida albicans and fluconazole. Proteomics 9: 4627-4631.

51. De Carolis E, Vella A, Florio AR, Posteraro P, Perlin DS, Sanguinetti M, Posteraro B (2012) Use of matrix-assisted laser desorption ionization-time of flight mass spectrometry for caspofungin susceptibility testing of Candida and Aspergillus species. J Clin Microbiol 50: 2479-2483.

52. Vella A, De Carolis E, Vaccaro L, Posteraro P, Perlin DS, Kostrzewa M, Posteraro B, Sanguinetti M (2013) Rapid antifungal susceptibility testing by matrix-assisted laser desorption ionization-time of flight mass spectrometry analysis. J Clin Microbiol 51: 2964-2969.

53. Seibold E, Maier T, Kostrzewa M, Zeman E, Splettstoesser W (2010) Identification of Francisella tularensis by whole-cell matrix-assisted laser desorption ionization-time of flight mass spectrometry: fast, reliable, robust, and cost-effective differentiation on species and subspecies level. J Clin Microbiol 48: 1061-1069.

54. Lartigue MF, Héry-Arnaud G, Haguenoer E, Domelier AS, Schmit PO, van der Mee-Marquet N, Lanotte P, Mereghetti L, Kostrzewa M, Quentin R (2009) Identification of Streptococcus agalactiae isolates from various phylogenetic lineages by matrix-assisted laser desorption ionization-time of flight mass spectrometry. J Clin Microbiol 47: 2284-2287.

55. Espinal P, Seifert H, Dijkshoorn L, Vila J, Roca I (2011) Rapid and accurate identification of genomic species from the Acinetobacter baumannii (Ab) group by MALDI-TOF MS. Clin Microbiol Infect 18: 1097-1103.

56. Mencacci A, Monari C, Leli C, Merlini L, De Carolis E, Vella A, Cacioni M, Buzi S, Nardelli E, Bistoni F, Sanguinetti M, Vecchiarelli A (2013) Typing of nosocomial outbreaks of Acinetobacter baumannii by use of matrix-assisted laser 
desorption ionization-time of flight mass spectrometry. J Clin Microbiol 51: 603-606.

57. Stephan R, Cernela N, Ziegler D, Pflüger V, Tonolla $\mathrm{M}$, Ravasi D, Fredriksson-Ahomaa M, Hächler H (2011) Rapid species specific identification and subtyping of Yersinia enterocolitica by MALDI-TOF mass spectrometry. J Microbiol Methods 87: 50-53.

58. Harris LG, El-Bouri K, Johnston S, Rees E, Frommelt L, Siemssen N, Christner M, Davies AP, Rohde H, Mack D (2010) Rapid identification of staphylococci from prosthetic joint infections using MALDI-TOF mass-spectrometry. Int $\mathbf{J}$ Artif Organs 33: 568-574.

\section{Corresponding author}

Prof. Maurizio Sanguinetti

Institute of Microbiology, Università Cattolica del Sacro Cuore

Largo F. Vito 1, 00168 Rome, Italy

Phone: $+39-630154218$

Fax: +39-63051152

Email: msanguinetti@rm.unicatt.it

Conflict of interests: No conflict of interests is declared. 